\title{
Family Functioning and Its Relation to Parental Discipline
}

\author{
Joana Carvalho $^{1} \cdot$ Otília Monteiro Fernandes $^{1} \cdot$ Inês Carvalho Relva $^{1,2}$
}

(C) Springer Science+Business Media New York 2017

\begin{abstract}
The Family Adaptability and Cohesion Scales (FACES) are one of the most used instruments in the study of family relations, assessing relevant dimensions of family functioning. This study aims to examine the relationship between cohesion, communication and family satisfaction, measured by FACES IV, and the dimensions of discipline inventory (DDI). The sample consisted of 380 subjects (190 adolescents and 190 parents). Fathers are the main users of physical discipline and boys are the main targets of most discipline practices. Regarding the association of the DDI and FACES, families with a balanced cohesion use less punitive discipline, families with enmeshed cohesion and families with disengaged cohesion have higher and less use of the analyzed disciplinary practices respectively. Considering the results, it may be useful to work together with families to promote the use of positive disciplinary methods and work their communication skills in order to improve cohesion and consequently family satisfaction.
\end{abstract}

Keywords Cohesion - Communication - Satisfaction . FACES IV · Discipline $\cdot$ DDI

Joana Carvalho

joana_1_4@live.com.pt

Otília Monteiro Fernandes

tila@utad.pt

Inês Carvalho Relva

irelva@utad.pt

1 Department of Education and Psychology, University of Trás-os-Montes e Alto Douro, Polo I, Quinta de Prados, 5000-801 Vila Real, Portugal

2 Centre for Social Studies of University of Coimbra, Coimbra, Portugal

\section{Introduction}

The family, due to their socialization and breeding functions is the basic social institution, providing the first learning to its elements (Alarcão, 2000; Knox \& Schacht, 2008). Over time, children tend to move from family dependency, to adolescence, and becoming gradually independent as they reach adulthood (Antonucci, Wong, \& Trinh, 2012). Although there are important periods of transition in family expectations and dynamics such coming into adulthood (Arnett, 2000), family dynamics change at every point in the life cycle of both the family and its elements (Antonucci et al., 2012). Family interdependence is increasingly felt not only with the younger generations of a family, but also with the older ones, and families nowadays seem to provide care for adolescents and young adults, but also for elderly parents (Grundy \& Henretta, 2006). Pimentel (2015) points out that elderly people who maintain their independence and who are still autonomous can also be a support base for the family (helping in financial terms, housework and care of grandchildren for example). Grandparent that are caregivers, in addition to providing help taking care of grandchildren, help strengthen generational bonds and a sense of belonging and security in the family (Pimentel, 2015).

The family system is considered to have the same properties as the open systems (Bertalanffy, 1972), one of these properties is the totality, meaning that it is relevant to look at the family as a whole in order to perceive the way it works, not being seen only as the sum of its individual parts. It is also important to note that the behavior of one of the elements is inseparable from the other elements and that what happens to one of them influences the whole family system (Alarcão, 2000). The way a family functions influences the individual's development and their identity. The sense of belonging and autonomy are relevant 
aspects of the subject formation, it is in the family context that we should develop a sense of belonging, and after be able to progress to being autonomous (Minuchin, Rosman, \& Baker, 1978).

\section{Family Functioning and the Circumplex Model of Marital and Family Systems}

Family functioning is defined as the ability of a family system to work as a whole and adjust itself to different situations especially the ones that cause stress (Alarcão, 2000; Minuchin et al., 1978).

The Circumplex Model of marital and family systems (hereinafter referred as Circumplex Model) focuses on three key concepts for the understanding of family functioning: cohesion, adaptability and communication. Cohesion is considered as the emotional bonds between family members (Olson, 2000, 2011). Adaptability is considered as the quality and expression of organization and leadership, roles and rules of the relations, and negotiation and focuses on how family manages stability and change (Olson, 2011). Communication is considered the communication skills used in the family system, and allows for changes in the level of cohesion or adaptability (Olson, 2000, 2011). Family satisfaction, although not part of the Circumplex Model is relevant to family functioning as it evaluates satisfaction with cohesion and family adaptability and the degree to which family members feel happy and fulfilled with each other (Barnes \& Olson, 1985; Olson, 2000).

The main hypothesis of Circumplex Model is that families with a healthy functioning feature balanced levels of cohesion and adaptability and better levels of communication and families with a problematic functioning are characterized by extreme/unbalanced levels of adaptability and cohesion and worst levels of communication (Olson, 2000, 2011). Families with unbalanced cohesion and adaptability levels have worse levels of family satisfaction when compared to balanced families (families with balanced levels of cohesion and adaptability) (Visani, 2014).

Balanced family and conjugal systems (both in terms of cohesion and adaptability) tend to be more functional, whereas high levels of cohesion (enmeshed systems) and adaptability (chaotic systems), and low levels of cohesion (disengaged systems) and adaptability (rigid systems) lead to long-term problems (for individuals and for their relationships) (Olson \& Gorall, 2003). Enmeshed cohesion can be understood as an extremely close relationship, characterized by dependence and reactivity of one subject to another, with little personal separation and little privacy. A disengaged cohesion is seen as having very separate relationships between family members, with little involvement and mutual support among its members (Olson \& Gorall, 2003). In regards of the adaptability, rigid adaptability is characterized by the existence of a family member responsible for decision making, the fact that the rules do not change and roles are well defined. Families with a chaotic adaptability have limited leadership, unclear roles and decisions are made impulsively.

\section{Parental Discipline}

Discipline is everything the parent does that affects the moral and psychological development of the child (Fauchier \& Straus, 2010). Many studies that have been conducted on how parents raise their children focus mainly on physical punishment (most of the research on how parents raise their children focuses on physical punishment) (Gershoff, 2002). Alternative disciplinary methods have not been targets of so much attention (Fauchier \& Straus, 2010).

Studies on physical punishment point to variables such as educational level of parents, gender and age of the parent and children, the number of children, the economic level of the family, to influence the greater or lesser use of this disciplinary method (Machado, Gonçalves, Matos, \& Dias, 2007; Straus, 2010; Straus \& Stewart, 1999). Depression, physical assault in marital relations and others, physical child abuse, alienation and masochistic sex are linked with parental use of physical punishment, especially when used until early adolescence (Straus, Sugarman, \& Giles-Sims, 1997). Corporal punishment appears yet to be associated to antisocial behavior (Gámez-Guadix, Carrobles, Almendros, \& Fernández-Alcaraz, 2010), aggression, lower levels of moral internalization and mental health (Gershoff, 2002), depression, suicide, alcohol abuse, and child and partner abuse (Straus \& Kantor, 1994). Lansford et al. (2005) also point to the relation between harsh use of corporal punishment and children's aggression and anxiety.

Although most of the literature about discipline has focused on physical punishment some have study other disciplinary alternatives. Calvete, Gámez-Guadix and Orue (2010) have found in that regarding physical punishment, boys are the main targets of most types of discipline (distraction, reward, physical punishment, withdrawal of privileges, compensation, ignore behavior and control), and mothers the main disciplinarian. The discipline used also varies with the age of the child. Positive discipline is most commonly used in young children, psychological aggression in older adolescents and physical punishment in young people between 12 and 14 years (Calvete et al., 2010). Comparing disciplinary methods used by Arab and Jewish mothers it was found that both culture and educational level of parents have an influence on practices used (Khoury-Kassabri \& Straus, 2011). The number of children and their birth order also influence the used disciplinary methods. Bigger families have more exposure to disciplinary methods, and older and middle children tend to be the 
main targets of disciplinary methods (Khoury-Kassabri \& Straus, 2011).

Gershoff et al. (2010), point that corporal punishment, yelling, and expressing disappointment were related with child aggressiveness, on the other hand time out, corporal punishment, expressing disappointment and shaming were related to anxiety.

Time out and removal of privileges have proven be effective in increasing compliance (Davies, McMahon, Flessati, \& Tiedemann, 1984). Time out also seems to be very effective as a long-term disciplinary method although it might not produce the desired effect immediately (Committee on Psychosocial Aspects of Child and Family Health, 1998). Despite this some authors argue that strategies such encouraging positive behavior, guidance, and trying to understand children's behavior are more positive than time out (Gartrell, 2001, 2002; Morawska \& Sanders, 2011). Using time out only by itself it is not recommended and the context in which it is applied also seems to be relevant (a warm and supportive environment it is best when applying this method) (Morawska \& Sanders, 2011).

The use of power assertive discipline (discipline that focus on physical punishment, psychological aggression, depravation of privileges and penalty tasks) seems to be link to negative outcomes when compared to inductive discipline parenting strategy that uses reasoning/explaning to help children understand how their behavior affects others, or are right or wrong (Power, Nuzzi, Narvaez, Lapsley, \& Hunt, 2007) that includes disciplinary behaviors such diversion, explanations, ignoring misbehavior, reward, and monitoring (Bosmans, Braet, Beyers, Van Leeuwen, \& Van Vlierberghe, 2011; Straus \& Fauchier, 2011). Power assertive discipline, usually promotes aggression, selfaggression, resistance to authority, as well as internalizing problems and less secure attachment (Becker, 1964; Bosmans et al., 2011). Inductive discipline on the other hand seems to be related to more empathy, prosocial behavior, increased moral identity in adolescents and lower levels of delinquency (Krevans \& Gibbs, 1996; Patrick \& Gibbs, 2012; Peiser \& Heaven, 1996; Power et al., 2007).

Taking in to account that most studies focus only on physical punishment and studies that focus on the relation between disciplinary dimensions and cohesion, communication and family satisfaction in the Portuguese context are scarce, this study aims to: (a) explore how the different disciplinary dimensions vary with the sex of teenagers, and the sex of the parents; (b) to analyze the perspective of family functioning from the point of view of children and their respective parents; (c) confirm the relationship between the different disciplinary dimensions and cohesion, communication and family satisfaction; and (d) confirm the predictive effect of cohesion, family communication and satisfaction in the disciplinary practices.

\section{Methods}

\section{Participants}

The sample was collected randomly in grade and secondary schools. From the 3880 questionnaires delivered to all the different schools, only 504 pares were returned (the ones returned without a pair were deemed incomplete). None of the schools allowed the investigators to be present at the time of application there for it is not possible to determine who may students or parents refused to participate or simply lost the protocols delivered to them. The final sample consisted of 380 subjects, 190 students, aged between 12 and 17 years $(M=13.93, S D=1.40)$, and one of their parents (190), aged between 30 and 61 years $(M=43.84, S D=6.07)$. For adolescents, and as regards sex, more than half of the sample was female $(65.3 \%)$. The level of education of adolescents ranged between 7 and 12 years $(21.6 \%$ of 7 th grade, $43.2 \%$ of 8 th grade, $11.1 \%$ of 9 th grade, $6.2 \%$ of 10 th grade, $13.2 \%$ of 11 th grade and $4.7 \%$ of 12 th year). Regarding parents, most of the respondents were females $(83.7 \%)$, most were married $(80.5 \%), 13.2 \%$ divorced, $4.7 \%$ in cohabitation, $1.1 \%$ were widows and $0.5 \%$ were single. Descriptive statistics of the sample can be seen on Table 1 .

\section{Procedures}

Data was collected in eleven public schools in the north of Portugal. A meeting was held with school directors in order to choose which classes would participate (base on age of students, schedule and acceptance of class director to participate). After defining how many classes were to participate, investigators delivered the informed consents and the protocols to the class directors which in turn distributed the informed consents among the students. To the students who obtained permission was then given a pair of questionnaires, one directed to them and the other one to their parents. Students filled the questionnaires in the classroom and afterwards delivered the protocol to their parents. The students were then responsible for returning the questionnaires to class directors.

\section{Measures}

The sociobiographical questionnaire (QSB) aimed collected information about the subject (such as gender, age and grade) the family and fraternal subsystem (age, number of siblings, parents' marital status and socio-economic status). The sociodemographic questionnaire directed to parents aimed to collect information related to variables such 
Table 1 Descriptive statistics of the sample

\begin{tabular}{ll}
\hline Socio-demografic characteristics & \\
\hline Adolescents' sex & \\
Female & $65.3 \%$ \\
Male & $34.7 \%$ \\
Adolescents' age & \\
Mean (SD) (13.93, 1.40) & $12-17$ years \\
Level of adolescents' education & \\
7th grade & $21.6 \%$ \\
8th grade & $43.2 \%$ \\
9th grade & $11.1 \%$ \\
10th grade & $6.2 \%$ \\
11th grade & $13.2 \%$ \\
12th grade & $4.7 \%$ \\
Parents' sex & \\
Female & $83.7 \%$ \\
Male & $16.3 \%$ \\
Parents' age & \\
Mean (SD) (43.84, 6.07) & $30-61$ years \\
Parents' marital status & \\
Married & $80.5 \%$ \\
Divorced & $13.2 \%$ \\
In cohabitation & $4.7 \%$ \\
Widows & $1.1 \%$ \\
Single & $0.5 \%$ \\
\hline
\end{tabular}

$S D$ standard-deviation

as age, marital status, number of children, monthly income and level of education of both couple elements.

The Family Adaptability and Cohesion Evaluation Scales IV (FACES IV) (Olson, Gorall\& Tiesel, 2006; Olson, 2011; adapted to the Portuguese population by; Rebelo, 2008) aims to evaluate family cohesion and adaptability. The scale was created based on the Circumplex Model and consists of 42 items grouped into a total of 6 scales aimed to evaluate two constructs, cohesion and family adaptability, assessing positive aspects (balanced) and negative (unbalanced) of family functioning (Olson, 2011). This instrument consists of two balanced scales (balanced cohesion and balanced adaptability) and four unbalanced scales (the enmeshed and disengaged scales, evaluating cohesion, and chaotic and rigid scales, evaluating adaptability). The six scales are calculated by adding the items that constitute them. Although the overall scale presents a good internal consistency and validity, two of its scales (enmeshed and rigid) have low predictive validity for these constructs (Olson, 2011). In the present study we made use of the three scales that evaluate cohesion (balanced cohesion, enmeshed and disengaged), which were answered both by adolescents, and by parents. Apart from the use of FACES, it is recommended the use of two additional scales
(Olson, Gorall, \& Tiesel, 2004), which are: the Family Communication Scale (FCS) (Olson \& Barnes, 2004) and Family Satisfaction Scale (FSS) (Olson, 2004).

The FCS Olson and Barnes (2004) (translated by Rebelo, 2008), allows to evaluate the positive communication existing in a family system (Olson, 2011). Composed of ten items, which should be answered in a Likert scale with five different dimensions (from "strongly disagree" to "strongly agree"), higher results indicate a more positive communication.

The FSS (Olson, 2004) (translated by Rebelo, 2008), consists of ten items and it evaluates the degree of satisfaction with the cohesion and family adaptability. It must be answered through a Likert scale with five different levels ranging from "very dissatisfied" to "very satisfied", and the higher the results the higher the family satisfaction.

The dimensions of discipline inventory (DDI), an instrument created by Straus and Fauchier (2011) and translated by Relva and Fernandes (2013), was create as a brief instrument to measure multiple aspects of disciplinary behaviors used by parents (Fauchier \& Straus, 2010). The present study focused on the discipline behaviors used towards the adolescents that answered the questionnaire, therefore, Part $\mathrm{C}$ of the version for children and adolescents, was used. Part $\mathrm{C}$ consist of 26 items relating to disciplinary method used towards the subject to whom the questionnaire is applied during the last year. Each item is repeated since it must be answered separately for mother and father (Straus \& Fauchier, 2011). The answers are given in a Likert scale ranging from $\mathrm{N}$ (never), and 0 (last year but not in the previous year) 9 (two or more times per day). The DDI allows to calculate different scales and thus to obtain different information about the disciplinary practices used by parents. In the present study, the four scales/first order factors of DDI that will be used are: supervision (that include monitoring behaviors and ignoring bad behavior of the children/adolescents), penalty (which includes the use of disciplinary methods as deprivation of privileges and penalizing tasks and restorative behaviors), positive discipline (including distraction, explain/teach and reward) and aggressive discipline (which includes physical and psychological punishment). These factors result from the grouping of nine scales of general disciplinary dimensions of DDI (Calvete et al., 2010; Straus \& Fauchier, 2011; Van Leeuwen, Fauchier, \& Straus, 2012).

Regarding the internal consistency of FACES IV for this sample, the reliability values were: 0.79 for both adolescents and parents for balanced cohesion scale; 0.73 for both adolescents and parents for disengaged unbalanced scale; 0.72 (adolescents) and 0.61 (parents) for enmeshed unbalanced scale. Regarding confirmatory factor analyzes for adolescents the adjustment of values was confirmed, being $\chi^{2}(24)=59,747 ; p=.000 ;$ Ratio $=2.390 ; \mathrm{CFI}=0.93$; 
$\mathrm{RMR}=0.038$ and RMSEA $=0.09$, also being confirmed for parents: $\chi^{2}(24)=40,082 ; p=.020$, ratio $=1.67 ; \mathrm{CFI}=0.97$; $\mathrm{RMR}=0.027$ and RMSEA $=0.06$.

Internal consistency for the FCS in this sample presented a alpha value of 0.92 for the adolescents and 0.86 for parents. Regarding the confirmatory factor analysis the adjustment was confirmed both for adolescents, $\chi^{2}(30)=74,170$; $p=.000 ; \quad$ Ratio $=2.472 ; \quad \mathrm{CFI}=0.96 ; \quad \mathrm{RMR}=0.035$ and RMSEA $=0.09$, both for parents $\chi^{2}(32)=83,801$; $p=.000 ; \quad$ Ratio $=2.619 ; \quad \mathrm{CFI}=0.93 ; \quad \mathrm{RMR}=0.032$ and RMSEA $=0.09$.

Concerning the internal consistency for the FSS, the alpha value was of 0.95 for adolescents and 0.94 for parents. With regard to confirmatory analysis, the adjustment was confirmed for adolescents $\chi^{2}(30)=71,409$; $p=.000, \quad$ Ratio $=2.380 ; \quad \mathrm{CFI}=0.98 ; \quad \mathrm{RMR}=0.025$ and RMSEA $=0.09$, and for parents, $\chi^{2}(32)=75,974$; $p=.000 ; \quad$ Ratio $=2.374 ; \quad \mathrm{CFI}=0.97 ; \quad \mathrm{RMR}=0.023$ and RMSEA $=0.09$.

Regarding internal consistency of the DDI scales values of positive discipline for mother was 0.76 and father 0.80 ; alpha for the aggressive discipline scale for mother was 0.79 and for father it was 0.80 , concerning the penalty scale for mother's alpha was 0.76 and 0.80 for fathers, finally for supervision scale alpha values for mother and father were 0.63 and 0.67 respectively. Regarding confirmatory factor analysis for the mother of DDI adjustment values was confirmed, $\chi^{2}(63)=180.70 ; p=.000 ;$ Ratio $=2.868 ; \mathrm{CFI}=0.91$; $\mathrm{RMR}=0.264$ and RMSEA $=0.10$ also been confirmed for the father $\chi^{2}(64)=183.65 ; p=.000 ;$ Ratio $=2.870$; $\mathrm{CFI}=0.93 ; \mathrm{RMR}=0.250$ and $\mathrm{RMSEA}=0.10$.

\section{Compliance with Ethical Standards}

\section{Ethical Approval}

All procedures performed in studies involving human participants were in accordance with the ethical standards of the institutional and/or national research committee and with the 1964 Helsinki declaration and its later amendments or comparable ethical standards. Informed consent was obtained from all individual participants included in the study.

\section{Data Analysis Strategies}

Data analysis was performed using the Statistical Package for the Social Statistical Sciences-IBM SPSS, version 22.0, the coding of the instruments and the creation of the database was made in this program. The Structural Equation Modeling Software-EQS for Windows, version 6.1 was also used to verify the psychometric properties of the instruments used.
Initially we proceeded to clean the sample by identify possible missing values and outliers that could undermine the study and the reliability of results. The analysis of outliers was obtained by determining Zscores and Mahalanobis distance. The normality of the sample was calculated by using the statistical inference process of the normal distribution or Gauss. After analyzing the Skeweness and Kourtosis values and considering that, according Maroco (2007), when the sample exceeds 30 subjects the normal distribution of a sample is accepted, parametric tests were used in the analyses. Psychometric analyzes using Cronbach's alpha and factor analysis were also carried out. Regarding data analyses $t$ tests, for independent and pair samples were used to analyze differences between disciplinary methods regarding the sex of the adolescent and the perceptions of parent and also of adolescent on family's cohesion, communication and satisfaction. Pearson correlations were also performed in order to analyze the association between disciplinary dimensions and parents' perspective of family cohesion, communication and satisfaction. According to Cohen (1988), correlations with values between 0.10 and 0.29 are small, between 0.30 and 0.49 are averages and between 0.50 and 1.0 are high. A hierarchical multiple regression was performed in order to verify the prediction of disciplinary dimensions used by both parents, of adolescents' sex and family functioning, communication and family satisfaction.

\section{Results}

\section{Differential Analysis of Disciplinary Dimensions According to the Sex of Adolescents}

In order to analyze the difference between disciplinary methods regarding the sex of the children we utilized the $t$ test. The results (Table 2) showed that there are significant differences in disciplinary dimensions, namely aggressive discipline, when used by the father $[t(96,948)=-2.029 ; p=.045]$, with $95 \%$ IC $[-6.66$, -0.07], being males $(M=10.05, S D=12.11)$ the main target compared to females $(M=6.68, S D=8.13)$. The penalty scale also showed significant differences regardless of the parent who applies this kind of discipline $[t(111,464)=-2.871 ; p=.005]$, with 95\% IC [-7.14, $-1.31]$ for mother and $[t(103,528)=-3.214 ; p=.002]$ with $95 \%$ IC $[-8.16,-1.93]$ for father, with males being the primary target of both mother $(M=6.12, S D=10.28)$ and father $(M=11.70, S D=11.22)$ compared to females who presented mean values of $(M=7.84, S D=8.35)$ for mothers and $(M=6.65, S D=8.28)$ for fathers. Supervision also showed significant differences for both parents $[t(188)=-2.650 ; p=.009]$, with $95 \%$ IC $[-3.90,-0.57]$ 
Table 2 Differential analysis of discipline dimensions according with adolescents' sex

\begin{tabular}{llccc}
\hline DDI-C & Sex & $M \pm S D$ & IC 95\% & $p$ value \\
\hline Mother's positive discipline & 1-Female & $19.40 \pm 12.03$ & {$[-4.51,2.73]$} & n.s. \\
& 2-Male & $20.29 \pm 12.11$ & & \\
Father's positive discipline & $1-$ Female & $17.41 \pm 12.76$ & {$[-6.32,1.30]$} & n.s. \\
& 2-Male & $19.92 \pm 12.58$ & & \\
Mother's aggressive discipline & 1-Female & $8.06 \pm 8.88$ & {$[-4.95,0.87]$} & n.s. \\
& 2-Male & $10.11 \pm 11.04$ & & \\
Father's aggressive discipline & 1-Female & $6.68 \pm 8.13$ & {$[-6.66,-0.07]$} & .045 \\
& 2-Male & $10.05 \pm 12.11$ & & \\
Mother's penalty & $1-$ Female & $7.84 \pm 8.35$ & {$[-7.14,-1.31]$} & .005 \\
Father's penalty & 2-Male & $12.06 \pm 10.28$ & & \\
& $1-$ Female & $6.65 \pm 8.28$ & {$[-8.16,-1.93]$} & .002 \\
Mother's supervision & 2-Male & $11.70 \pm 11.22$ & & \\
& $1-$ Female & $3.85 \pm 5.28$ & {$[-3.90,-0.57]$} & .009 \\
Father's supervision & 2-Male & $6.09 \pm 5.99$ & & \\
& $1-$ Female & $3.45 \pm 5.10$ & {$[-4.01,-0.63]$} & .007 \\
\hline
\end{tabular}

$D D I-C$ dimensions of discipline questionnaire, form C, $M$ mean, $S D$ standard-deviation, $I C_{95 \%}$ interval of confidence $95 \%$ for mother and $[t(188)=-2.714 ; p=.007]$ for father, with 95\% CI [-4.01, -0.63], males also appeared to be the main target $(M=6.09, S D=5.99)$ for both mother and $(M=5.77$, $S D=0.47)$ father, when compared to females $(M=3.85$, $S D=5.28)$ for the mother and $(M=3.45, S D=5.10)$ for the father.

\section{Differential Analysis of Parent and Adolescents' Perspective of Family Cohesion, Communication and Satisfaction}

In order to analyze the difference between the perception of cohesion, communication and family satisfaction between parents and children we carried out a $t$ test for paired samples. The results (Table 3) show that there are significant differences in the perception of balanced cohesion of parents and children $[t(189)=2.81, p=.006$ (two-tailed)], with 95\% IC [0.23, 1.34], with parents presenting a higher mean $(M=27.78, S D=3.74)$ when compared to the children $(M=26.99, S D=4.12)$. It was also found that there are significant differences in the disengaged scale $[t(189)=-3.34, p=.001$ (two-tailed)], with $95 \%$ IC $[-1.86,-0.48]$, with children registering $(M=16.53, S D=4.23)$ higher results when compared to parents $(M=15.36, S D=3.90)$. The enmeshed cohesion also showed statistically significant differences, $[t(189)=-2.13, p=.035$ (two-tailed) $]$, with $95 \%$ CI $[-1.13,-0.04]$, the children $(M=18.23, S D=4.23)$ registered an higher mean than that of parents $(M=17.65$, $S D=3.48)$. Communication also presented statistically
Table 3 Differential analysis of parent and adolescents' perspective of family cohesion, communication and satisfaction

\begin{tabular}{lllll}
\hline FACES IV & Family's elements & $M \pm S D$ & IC 95\% & $p$ value \\
\hline Balanced cohesion & 1-Parents & $27.78 \pm 3.74$ & {$[0.23,1.34]$} & .006 \\
& 2-Adolescents & $26.99 \pm 4.12$ & & \\
Disengaged cohesion & 1-Parents & $15.36 \pm 3.90$ & {$[-1.86,-0.48]$} & .001 \\
& 2-Adolescents & $16.53 \pm 4.23$ & & \\
Enmeshed cohesion & 1-Parents & $17.65 \pm 3.48$ & {$[-1.13,-0.04]$} & .035 \\
& 2-Adolescents & $18.23 \pm 4.23$ & & \\
Communication & 1-Parents & $39.29 \pm 5.00$ & {$[0.42,2.16]$} & .004 \\
& 2-Adolescents & $38.01 \pm 7.02$ & & \\
Family satisfaction & 1-Parents & $37.12 \pm 6.97$ & {$[-1.80,0.44]$} & n.s. \\
& 2-Adolescents & $37.80 \pm 7.96$ & & \\
\hline
\end{tabular}

FACES IV Family Adaptability and Cohesion Scale IV, $M$ mean, $S D$ standard-deviation, $I C_{95 \%}$ interval of confidence $95 \%$ 
significant differences $[t(189)=2.91, p=.004$ (twotailed)], with $95 \%$ IC $[0.42,2.16]$ with parents presenting higher means $(M=39.29, S D=5)$ when compared to adolescents $(M=38.01, S D=7.02)$.

\section{Association Between Disciplinary Dimensions, Cohesion, Communication and Family Satisfaction According to Parents' Perspective, Means and Standard Deviation}

In order to verify the relationship between disciplinary dimensions and family cohesion, communication and satisfaction, we conducted a Pearson correlation. Regarding this analysis (Table 4), there was a low positive association between enmeshed cohesion of parents and mother's $(r=0.197 ; p \leq .01)$ and father's supervision $(r=0.157 ; p \leq .05)$. It was also verified a low negative association between balanced cohesion of parents and aggressive discipline of both mother $(r=-0.194$; $p \leq .01)$ and father $(r=-0.182 ; p \leq .05)$. The same type of association was observed between the communication of parents and father's aggressive discipline $(r=-0.152$; $p \leq .05)$; between family satisfaction of parents and mother's $(r=-0.172 ; p \leq .05)$ and father's $(r=-0.193$; $p \leq .01)$ aggressive discipline and between family satisfaction of parents and the penalty scale of the mother $(r=-0.164 ; p \leq .05)$.
Predictive Analysis: The Predictor Role of Adolescents' Sex, Cohesion, Communication and Family Satisfaction in the Disciplinary Dimensions

Multiple hierarchical regressions were held in order to assess the predictive power of family functioning (cohesion, communication and family satisfaction), according to the parents' perspective, in the different disciplinary dimensions (Table 5). Block 1 corresponded to the dummy variable, sex of the adolescent (being 0 for females and 1 male), and Block 2 corresponded to the variables of FACES IV.

Regarding the variable positive discipline of the mother, Block 1 explained $0.1 \%$ of the total variance in the positive discipline $\left(R^{2}=0.001\right)$ individually contributing to $0.1 \%$ of the variance for the model $\left(R^{2}\right.$ change $\left.=0.001\right)$ not presenting a significant contribution $[F(1,188)=0.236 ; p=.628]$. Block 2 has a significant contribution $[F(6,183)=2.261$; $p=.040]$ and explains $6.9 \%$ of the total variance $\left(R^{2}=0.069\right)$ individually contributing to $6.8 \%$ of the variance for the model $\left(R^{2}\right.$ change $\left.=0.068\right)$. Analyzing the individual contribution of each of the independent variables of the blocks, it appears that two variables have a significant contribution $(p \leq .05)$ and predict the positive discipline of the mother: disengaged cohesion $(\beta=-0.330)$ and enmeshed cohesion $(\beta=0.249)$.

Regarding father's positive discipline, Block 1 explains $0.9 \%$ of the total variance $\left(R^{2}=0.009\right)$ and contributes individually with $0.9 \%$ of the variance to the model $\left(R^{2}\right.$ change $\left.=0.009\right)$ not presenting a significant contribution

Table 4 Association between discipline dimensions, cohesion, communication and family satisfaction according to parents' perspective, means and standard deviation

\begin{tabular}{|c|c|c|c|c|c|c|}
\hline FACES IV & $\begin{array}{l}\text { 1. Balanced cohe- } \\
\text { sion }\end{array}$ & $\begin{array}{l}\text { 2. Disengaged cohe- } \\
\text { sion }\end{array}$ & $\begin{array}{l}\text { 3. Enmeshed cohe- } \\
\text { sion }\end{array}$ & 4. Communication & $\begin{array}{l}\text { 5. Family satisfac- } \\
\text { tion }\end{array}$ & $M \pm S D$ \\
\hline \multicolumn{7}{|l|}{ DDI-C } \\
\hline $\begin{array}{l}\text { 6. Mother's positive } \\
\text { discipline }\end{array}$ & 0.015 & -0.110 & 0.110 & 0.14 & -0.37 & $19.71 \pm 12.03$ \\
\hline $\begin{array}{l}\text { 7. Father's positive } \\
\text { discipline }\end{array}$ & -0.008 & -0.094 & 0.082 & 0.21 & -0.27 & $18.28 \pm 12.72$ \\
\hline $\begin{array}{l}\text { 8. Mother's aggres- } \\
\text { sive discipline }\end{array}$ & $-0.194 * *$ & 0.066 & 0.124 & -0.139 & $-0.172 *$ & $8.77 \pm 9.70$ \\
\hline $\begin{array}{l}\text { 9. Father's aggres- } \\
\text { sive discipline }\end{array}$ & $-0.182^{*}$ & 0.084 & 0.133 & $-0.152^{*}$ & $-0.193^{* *}$ & $7.85 \pm 9.80$ \\
\hline $\begin{array}{l}\text { 10. Mother's } \\
\text { penalty }\end{array}$ & -0.065 & -0.022 & 0.119 & -0.101 & $-0.164 *$ & $9.31 \pm 9.26$ \\
\hline 11. Father's penalty & -0.074 & 0.000 & 0.123 & -0.098 & -0.139 & $8.41 \pm 9.68$ \\
\hline $\begin{array}{l}\text { 12. Mother's super- } \\
\text { vision }\end{array}$ & -0.046 & -0.016 & $0.197 * *$ & -0.085 & -0.093 & $4.63 \pm 5.63$ \\
\hline $\begin{array}{l}\text { 13. Father's super- } \\
\text { vision }\end{array}$ & -0.122 & 0.002 & $0.157^{*}$ & -0.111 & -0.111 & $4.26 \pm 5.71$ \\
\hline$M \pm D P$ & $27.78 \pm 3.74$ & $15.36 \pm 3.90$ & $17.65 \pm 3.47$ & $29.29 \pm 5.00$ & $37.12 \pm 6.97$ & \\
\hline
\end{tabular}

FACES IV Family Adaptability and Cohesion Scale IV, DDI-C dimensions of discipline questionnaire, form C, $M$ mean, $S D$ standard-deviation $* p \leq .05, * * p \leq .01$ 
Table 5 The predictor role of adolescents' sex, cohesion, communication and family satisfaction in the discipline dimensions

\section{$R^{2} \quad R^{2}$ change $\mathrm{B}$}

S. error

$\beta$

Mother's positive discipline

Block 1

Adolescents' sex (dummy)

$0.001 \quad 0.001$

Block 2

FACES IV parents

Balanced cohesion of parents

Disengaged cohesion of parents

Enmeshed cohesion of parents

Communication of parents

Family satisfaction of parents

Father's positive discipline

Block 1

Adolescents' sex (dummy)

Block 2

FACES IV parents

Balanced cohesion of parents

Disengaged cohesion of parents

Enmeshed cohesion of parents

Communication of parents

Family satisfaction of parents

Mother's aggressive discipline

Block 1

Adolescents' sex (dummy)

Block 2

FACES IV parents

$\begin{array}{rrrrr}-0.546 & 0.245 & -0.211 & -2.224 & .027 \\ -0.529 & 0.262 & -0.213 & -2.002 & .045 \\ 0.476 & 0.231 & 0.171 & 2.060 & .041\end{array}$

Disengaged cohesion of parent

Enmeshed cohesion of parents

Communication of parents

Family satisfaction of parents

Father's aggressive discipline

Block 1

Adolescents' sex (dummy)

Block 2

FACES IV parents

$0.027 \quad 0.027$

1.454

0.143

2.022

.045

$0.097 \quad 0.070$

Balanced cohesion of parents

Disengaged cohesion of parents

Enmeshed cohesion of parents

Communication of parents

Family satisfaction of parents

Mother's penalty

Block 1

Adolescents' sex (dummy)

Block 2

FACES IV parents

$0.047 \quad 0.047$

$3.821 \quad 1.359$

0.197

2.812

.005

$0.117 \quad 0.070$

Balanced cohesion of parents

Disengaged cohesion of parents

Enmeshed cohesion of parents

Communication of parents

Family satisfaction of parents

\begin{tabular}{rrrrr}
-0.645 & 0.245 & -0.271 & -2.631 & .009 \\
0.579 & 0.217 & 0.217 & 2.671 & .008 \\
& & & & \\
-0.296 & 0.115 & -0.223 & -2.565 & .011 \\
\hline
\end{tabular}


Table 5 (continued)

\begin{tabular}{|c|c|c|c|c|c|c|c|}
\hline & $R^{2}$ & $R^{2}$ change & $\mathrm{B}$ & S. error & $\beta$ & $t$ & $p$ \\
\hline \multicolumn{8}{|l|}{ Father's penalty } \\
\hline \multicolumn{8}{|l|}{ Block 1} \\
\hline Adolescents' sex (dummy) & 0.062 & 0.062 & 4.702 & 1.424 & 0.232 & 3.301 & .001 \\
\hline \multicolumn{8}{|l|}{ Block 2} \\
\hline FACES IV parents & 0.112 & 0.050 & & & & & \\
\hline \multicolumn{8}{|l|}{ Balanced cohesion of parents } \\
\hline Disengaged cohesion of parents & & & -0.536 & 0.257 & -0.216 & -2.087 & .038 \\
\hline Enmeshed cohesion of parents & & & 0.554 & 0.227 & 0.199 & 2.437 & .016 \\
\hline \multicolumn{8}{|l|}{ Communication of parents } \\
\hline \multicolumn{8}{|l|}{ Family satisfaction of parents } \\
\hline \multicolumn{8}{|l|}{ Mother's supervision } \\
\hline \multicolumn{8}{|l|}{ Block 1} \\
\hline Adolescents' sex (dummy) & 0.036 & 0.036 & 2.039 & 0.826 & 0.173 & 2.462 & .015 \\
\hline \multicolumn{8}{|l|}{ Block 2} \\
\hline FACES IV parents & 0.115 & 0.079 & & & & & \\
\hline \multicolumn{8}{|l|}{ Balanced cohesion of parents } \\
\hline Disengaged cohesion of parents & & & -0.393 & 0.149 & -0.273 & -2.638 & .009 \\
\hline Enmeshed cohesion of parents & & & 0.489 & 0.132 & 0.301 & 3.690 & .000 \\
\hline \multicolumn{8}{|l|}{ Communication of parents } \\
\hline \multicolumn{8}{|l|}{ Family satisfaction of parents } \\
\hline \multicolumn{8}{|l|}{ Father's supervision } \\
\hline \multicolumn{8}{|l|}{ Block 1} \\
\hline Adolescents' sex (dummy) & 0.038 & 0.038 & 2.066 & 0.842 & 0.173 & 2.455 & .015 \\
\hline \multicolumn{8}{|l|}{ Block 2} \\
\hline FACES IV parents & 0.107 & 0.069 & & & & & \\
\hline \multicolumn{8}{|l|}{ Balanced cohesion of parents } \\
\hline Disengaged cohesion of parents & & & -0.404 & 0.152 & -0.276 & -2.656 & .009 \\
\hline Enmeshed cohesion of parents & & & 0.401 & 0.134 & 0.244 & 2.984 & .003 \\
\hline \multicolumn{8}{|l|}{ Communication of parents } \\
\hline Family satisfaction of parents & & & & & & & \\
\hline
\end{tabular}

B, S. error and $\beta$ for a significance level of $p<.05$

FACES IV Family Adaptability and Cohesion Scale IV

$[F(1,188)=1.688 ; p=.195]$. Block 2 does not present a significant contribution $[F(6,183)=1.782 ; p=.105]$ explains $5.5 \%$ of the total variance $\left(R^{2}=0.055\right)$ and individually contributes $4.6 \%$ for the variance of the model $\left(R^{2}\right.$ change $\left.=0.046\right)$. Analyzing individually two of the independent variables have a significant contribution $(p \leq .05)$ and predict the positive discipline of the father: disengaged cohesion $(\beta=-0.278)$ and enmeshed cohesion $(\beta=0.198)$.

Regarding variable mother's aggressive discipline Block 1 explains $1 \%$ of the total variance $\left(R^{2}=0.010\right)$ individually contributing to $1 \%$ of the variance to the model $\left(R^{2}\right.$ change $\left.=0.010\right)$, not presenting a significant contribution $[F(1,188)=1.917 ; p=.168]$. Block 2 has a significant contribution $[F(6,183)=2.767 ; p=.013]$, explaining $8.3 \%$ of the total variance $\left(R^{2}=0.083\right)$ and explaining individually $7.3 \%$ of the variance for the model $\left(R^{2}\right.$ change $\left.=0.073\right)$. With regard to the contribution of each of the independent variables of the blocks, it can be seen that three variables have a significant contribution $(p \leq .05)$ and predict mother's aggressive discipline: balanced cohesion $(\beta=-0.211)$, disengaged cohesion $(\beta=-0.213)$ and enmeshed cohesion $(\beta=0.171)$.

Regarding the variable father's aggressive discipline, Block 1 explains $2.7 \%$ of the total variance $\left(R^{2}=0.027\right)$, contributes individually with $2.7 \%$ of the variance to the model $\left(R^{2}\right.$ change $\left.=0.027\right)$ and has a significant contribution $[F(1,188)=5,204 ; p=.024]$. Block 2 has a significant contribution $[F(6,183)=3.260 ; p=.005]$ explains $9.7 \%$ of the total variance $\left(R^{2}=0.097\right)$ and contributes individually with $7 \%$ of the variance for the model $\left(R^{2}\right.$ change $\left.=0.070\right)$. Individually three variables have a significant contribution $(p \leq .05)$ and predict father's aggressive discipline: the male gender $(\beta=0.143)$, the enmeshed cohesion of the parents $(\beta=0.171)$, the use of aggressive discipline and the level of 
family satisfaction of parents $(\beta=-0.179)$ predict this disciplinary dimension.

Regarding the variable mother's penalty Block 1 explains $4.7 \%$ of the total variance $\left(R^{2}=0.047\right)$, individually contributing with $4.7 \%$ of the variance to the model $\left(R^{2}\right.$ change $\left.=0.047\right)$ and presenting a significant contribution $[F(1,188)=9,343 ; p=.003]$. Block 2 has a significant contribution $[F(6,183)=4.046 ; p=.001]$ explains $11.7 \%$ of the total variance $\left(R^{2}=0.117\right)$ and contributes individually with $7 \%$ of the variance for the model ( $R^{2}$ change $=0.070$ ). As regards the individual contribution of each of the independent variables, it is noted that the four variables have a significant contribution $(p \leq .05)$ and predict the penalty scale when used by the mother: disengaged cohesion $(\beta=-0.271)$, family satisfaction $(\beta=-0.223)$, male gender $(\beta=0.197)$ and enmeshed cohesion $(\beta=0.217)$.

Regarding father's penalty Block 1 explains $6.2 \%$ of the total variance $\left(R^{2}=0.062\right)$, individually contributing $6.2 \%$ of the variance for the model $\left(R^{2}\right.$ change $\left.=0.062\right)$ presenting a significant contribution $[F(1,188)=12,390$; $p=.001]$. Block 2 also presents a significant contribution $[F(6,183)=3.849 ; p=.001]$ and explains $11.2 \%$ of the total variance $\left(R^{2}=0.112\right)$ individually contributing with $5 \%$ of the variance for the model $\left(R^{2}\right.$ change $\left.=0.050\right)$. Three of the variables have a significant individual contribution $(p \leq .05)$ and predict this variable: the disengaged cohesion $(\beta=-0.216)$, enmeshed cohesion $(\beta=0.199)$ and male gen$\operatorname{der}(\beta=0.232)$.

Regarding mother's supervision Block 1 explains 3.6\% of the total variance $\left(R^{2}=0.036\right)$, individually contributing $3.6 \%$ of the variance to the model $\left(R^{2}\right.$ change $\left.=0.036\right)$ presenting a significant contribution $[F(1,188)=7.021$; $p=.009$ ]. Block 2 has a significant contribution $[F(6,183)=3.953 ; p=.001]$, explaining $11.5 \%$ of the total variance $\left(R^{2}=0.115\right)$ and individually contributing with $7.9 \%$ to the variance of the model $\left(R^{2}\right.$ change $\left.=0.079\right)$. Disengaged cohesion, enmeshed cohesion and sex have a significant contribution $(p \leq .05)$ and predict mother's supervision. Disengaged cohesion $(\beta=-0.273)$, male gender $(\beta=0.173)$ and enmeshed cohesion $(\beta=0.301)$ predicted this variable.

Finally, concerning father's supervision it was found that Block 1 explains $3.8 \%$ of the total variance $\left(R^{2}=0.038\right)$ individually contributing with $3.8 \%$ of the variance for the model $\left(R^{2}\right.$ change $\left.=0.038\right)$ presenting a significant contribution $[F(1,188)=7,364 ; p=.007]$. Block 2 contributes in a significant mater $[F(6,183)=3.661 ; p=.002]$ explaining $10.7 \%$ of the total variance $\left(R^{2}=0.107\right)$ and contributes individually with 6.9 of the variance for the model $\left(R^{2}\right.$ change $\left.=0.069\right)$. Individually the independent variables that contribute significantly $(p \leq .05)$ and predict father's supervision are male gender $(\beta=0.173)$ and enmeshed cohesion $(\beta=0.244)$ that predict the use of this disciplinary method.

\section{Discussion}

The scientific papers that have discussed disciplinary practices used in the education of children mainly reflect the punitive practices at a physical level (Gershoff, 2002), other disciplinary strategies (such as the reinforcement of desirable behavior and rationalization) have received less attention (Fauchier \& Straus, 2010). Thus, this study aimed, by using the DDI, to analyze different disciplinary dimensions used by parents and verify how these dimensions relate to some of the variables of family functioning (cohesion, communication and family satisfaction) and are predicted by these same variables.

Regarding the differences in disciplinary methods used by parents in relation to the sex of the children we verified that boys were the main targets of disciplinary actions when compared to girls about aggressive discipline (when it was applied by the father), penalty and supervision used by both parents. Other studies (Calvete et al., 2010) point in the same direction, that boys are the main targets of most discipline types (distraction, reward, physical punishment, withdrawal of privileges, compensation, ignore behavior and control), and that the father applies more control discipline and distraction with boys when compared to girls. Other studies (McKee et al., 2007; Straus \& Stewart, 1999) point in the same direction, presenting boys as the main targets of physical punishment when compared to girls. The fact that boys appear to be the main targets of the disciplinary practices may be because they are perceived as less submissive/ obedient than girls (Straus \& Stewart, 1999). McKee et al., (2007) also point to the fact that parents (especially fathers) may believe, because of the gender roles, that physical punishment is necessary to improve the behavior of boys but not in girls, which may explain the differences concerning the sex of the parents in the application of aggressive discipline in the present sample, in which fathers show an increased use of this method.

About the influence parents' sex in the disciplinary dimensions, Fauchier and Straus (2007) point to a similar involvement of both parents in the disciplinary practices of children, the same can be concluded with the present study, except for aggressive discipline that presents an increased usage by the father. McKee et al. (2007) point to the fact that father is the main perpetrator of physical punishment when compared with mothers. Moon and Hoffman (2008) state that although the mother applies more disciplinary practices, the involvement of fathers in the discipline of boys has slightly increased. These results contradict the results obtained by other authors (Calvete et al., 2010; 
Machado et al., 2007; Moon \& Hoffman, 2008) in which the mother is primary disciplinary. Thus, by the results obtained, it is possible that the involvement of fathers in the disciplinary practices of children is increasing, and the stereotype of gender, in which the mother is the primary caregiver of the children, is being left behind which may partly be due to the greater inclusion of women in the labor market. Portugal, post 25 April 1974 (the day of the Carnation Revolution in which right-wing dictatorship known as Estado Novo was overthrown), suffered many changes. With the implementation of democracy and legislation change women started getting better education, and many entered the job market (Silva, 2010). Before the revolution, conceptions about the place and role of women in society, arguments for protecting the biological function of motherhood, were used to maintain the idea of subalternity of women and prohibitions on the exercise of some professions, salary and occupational discrimination also occurred (Monteiro, 2010). It is then possible that with the political changes that occurred after the revolution, not only gave way for women to enter in the job market, but also allowed social and cultural changes of what it means to be a woman and a mother allowing for a somewhat similar distribution of responsibility between a couple when it comes to raising children.

About the analysis of the differences between the perception of cohesion, communication and family satisfaction among parents and children the results show that parents have a more positive perspective of family functioning when compared to the children and the values of balanced cohesion and communication are superior to those of the children and the levels of disengaged and enmeshed cohesion are inferior to the levels perceived by children. Vidović, Juresa, Begovac, Mahnik, and Tocilj (2005) found that mothers of adolescents with eating disorders perceived their families more positively in terms of cohesion, adaptability and communication when compared to their daughters, justifying these differences with the fact that the mother may try to deny and avoid conflict, with the family idealization by mothers and the need for mothers to perceive their family positively. In adolescence, an emotional separation between adolescent and parents occurs, and with this change in their relationship, the peer group gains more importance and although adolescence is not always record serious conflicts between parents and adolescents, young people tend to behave in a way with which the parents do not agree (Graham, 2004). Thus, the increased importance given to peers at and conflicts with parents can lead teenagers to have a less positive perception of family environment. It may also be possible that the parents have responded in order give a more positive image of the family, to demonstrate a more positive family cohesion and more positive communication and go according to what is socially desirable, being teenagers more critical because they require emotional separation from their family, and this may be achieved easily when the parent and the family is viewed negatively.

Regarding the association between dimensions of family functioning, communication and family satisfaction and disciplinary dimensions it was possible to verify a negative association between balanced cohesion and punitive disciplinary methods applied by both parents. Some studies have found that families in which there are abusive disciplinary practices, including physical abuse, are perceived as less cohesive when compared with non-abusive families, being more dysfunctional than non-abusive families (Meyerson, Long,Miranda, \& Marx, 2002). Considering the results obtained in this study it is possible that, with the families being perceived by parents as balanced in terms of cohesion and as less dysfunctional, the parents may not resort to the use of punitive discipline practices to correct children's behaviors that they can consider as inadequate.

It was also found a positive association between the enmeshed cohesion and supervision of both parents, which may be because monitoring is the instrumental aspect of cohesion with the closeness among its members being the affective aspect of the cohesion (Robin, 1998). It was also possible to verify the existence of a negative association between the level of communication and the aggressive discipline applied by the father, and between family satisfaction with the use of aggressive discipline by both parents and the penalty scale of the mother. The results thus indicate that families with a lower level of communication present higher levels of aggressive discipline used by parents. As previously mentioned, communication is a mediator between the different levels of family functioning (Barnes \& Olson, 1985) and lower levels of communication in addition to being associated with extreme values of cohesion they may also be associated with more aggressive disciplinary practices by the parent. The literature points to a relationship between verbal violence and the use of physical punishment as a disciplinary methods and parents with lower communication skills can use these methods to deal with their children especially when other methods fail (Roberto, Carlyle, \& McClure, 2006). Family satisfaction presented a negative association with the aggressive discipline of both parents and the penalty scale of the mother. Ochoa, Sánchez, and Gracia (1988) also point to a positive association between deprivation of privileges by the parents and aggressiveness on the part of children, and to the fact that children how here targets of punitive practices tend to reproduce aggressive behavior. Thus, it may occur that family satisfaction as perceived by parents may decrease with the use of such practices, either because they can stimulate aggressive behavior in the children, either by the fact 
that parents may perceive such methods as ineffective and/ or counterproductive in reducing bad behavior.

Finally, it was also possible to verify the predictor role of enmeshed and disengaged cohesion in the disciplinary dimensions. It was found that enmeshed cohesion positively predicts the four types of disciplinary dimensions evaluated in this article. Considering the results obtained in this sample, the definition of enmeshed cohesion by Olson and Gorall (2003), cited above, it is possible that families with an enmeshed cohesion, that is, with too close relations, use different types of discipline due the over-involvement of its elements. When monitoring on the part of the parents is too much it can lead to family conflicts due to lack of privacy that excess monitoring involves (Robin, 1998), these family conflicts may lead the parents to use different disciplinary practices.

Regarding the disengaged cohesion, it has found that it predicts all disciplinary methods negatively (except the aggressive discipline of the father who did not reveal statistical significance). Thus, it is possible that, regarding to the definition presented by Olson and Gorall (2003), the separateness that characterize families with a disengaged cohesion may lead to parents not being as attentive to the behavior of the children, be it negative or positive, thus not applying so many disciplinary methods. Reduced closeness between parents and children may be reflected in how parents react to children's transgressions, and negligent parents may ignore the misbehavior of children (Ochoa et al., 1988).

It was also found that balanced cohesion negatively predicts mother's aggressive discipline. These results corroborate previous studies (Meyerson et al., 2002), which found that families in which physically abusive practices occurred were seen as less cohesive compared to families in which these practices were not registered. Thus it could be said that families had a more balanced cohesion when they did not use punitive practices, which supports the results obtained in this study.

Family satisfaction predicts mother's penalty and father's aggressive discipline in a negative way, that is, the greatest satisfaction in the family can lead to a more positive understanding of the family leading to a lesser need for parents to resort to these disciplinary methods. Many parents can make use of punitive methods even when they do not agree with them, and the emotional state of the parent at the time of application of the discipline may be the cause of its use (Cappa \& Khan, 2011). Thus, it is possible that when parents perceive a satisfactory family environment they tend to resort less to these disciplinary methods, since they may not agree with their use and apply them in situations that they perceive as more stressful.

Regarding the sex of the children we observed that the male sex predicts positively both the penalty scale and the supervision of both parents, and father's aggressive discipline. As stated earlier, parental discipline varies according to different factors, one being the sex of the children. The discipline addressed to boys seems to be different from that addressed to girls (Ochoa et al., 1988), being males the prime targets for punitive disciplinary practices (Straus \& Stewart, 1999) and other practices such as ignore behavior, control, physical punishment, withdrawal of privileges and rewards when compared to girls (Calvete et al., 2010).

\section{Practical Implications, Limitations and Suggestions for Further Studies}

This study becomes relevant for the fact that it analyzes the relationship between cohesion and different disciplinary dimensions that go beyond the physical punishment already analyzed in previous studies, and because it also includes the perspective of how communication and family satisfaction influence these practices. It is noteworthy that it was not found by us any literature that makes an association between all these variables. Given the results of this study the development of research projects that address these variables and combine with others (such as sociodemographic questions like income and educational level of the parents, for example) may be useful to better understand their role in the different disciplinary dimensions used by parents. The development of projects in the community, with the family, can also be positive to promote the use of more positive disciplinary methods (such as positive discipline), raising awareness to possible negative consequences of more punitive practices, and also working with families on the communicational skills among its members. It is also important that practitioners work with family members towards achieving and maintaining positive levels of communication, in the therapeutic setting or with educational programs. Working with family members in order to increase their positive communication, focusing, for example, in negotiation and teaching active listening tactics, may increase levels of family cohesion and satisfaction. Working for a better family communication, leading to a balance level of cohesion in the family, may lead for a better use of disciplinary practices by parents, contrary to the inconsistent use of disciplinary dimensions by the enmeshed families and potentially more negligent attitude of disengaged families.

This study has several limitations, including the sample size that may prevent the generalization of the results to the Portuguese population. The collection of data about the perspective of the parents about their disciplinary practices would have been interesting in order to make a comparison with the perspective of their children and to verify a possible relationship of this instrument answered by parents 
with their responses to FACES. It would also have been interesting to collect data from both parents instead of just one, as occurred in this study. This could have given a more complete perspective about family functioning. Another limitation of this study is the fact that researchers were not present at the time of fulfilling the protocols, therefore not being able to guarantee that parents answered FACES IV.

In future work it would become interesting to collect data from children to analyze to what extent the disciplinary dimensions vary according to different age groups, increase the size of the sample, collect the perspective of parents regarding disciplinary dimensions used and the beliefs that children and parents have on these same practices. The inclusion of other sociodemographic variables and the study of the other scales of FACES IV will also be relevant. Considering culture and its effect on family functioning might also be relevant for future studies and analysis on the topic of family function and discipline.

\section{References}

Alarcão, M. (2000). (des)Equilíbrios familiares. Coimbra: Quarteto.

Antonucci, T., Wong, K., \& Trinh, S. (2012). The role of the family across the lifespan. In P. Noller \& G. Karantzas (Eds.), The Wiley-Blackwell handbook of couples and family relationships (pp. 51-65). Oxford: John Wiley \& Sons.

Arnett, J. (2000). Emerging adulthood: A theory of development from the late teens through the twenties. American Psychologist, 55, 469. doi:10.1037//0003-066X.55.5.469.

Barnes, H., \& Olson, M. (1985). Parent-adolescent communication and the Circumplex Model. Journal of Child and Family Studies, 56, 438-447. doi:10.2307/1129732.

Becker, W. (1964). Consequences of different kinds of parental discipline. In L. Hoffman \& M. Hoffman (Eds.), Review of child development research (vol. 1, pp. 169-208). New York: Russel Sage Foundation.

Bertalanffy, L. (1972). Théorie général des systèmes. Paris: Dunod.

Bosmans, G., Braet, C., Beyers, W., Van Leeuwen, K., \& Van Vlierberghe, L. (2011). Parents' power assertive discipline and internalizing problems in adolescents: The role of attachment. Parenting: Science and Practice, 11, 34-55. 10.1080/15295192.2011.539507.

Calvete, E., Gámez-Guadix, M., \& Orue, I. (2010). El Inventario de Dimensiones de Disciplina (DDI), versión niños y adolescentes: Estudio de las prácticas de disciplina parental desde una perspectiva de género. Anales de Psicología, 26, 410-418.

Cappa, C., \& Khan, S. (2011). Understanding caregivers' attitudes towards physical punishment of children: Evidence from 34 lowand middle-income countries. Child Abuse \& Neglect, 35, 10091021. doi:10.1016/j.chiabu.2011.10.003.

Cohen, J. (1988). Statistical power analysis for the behavioral sciences. Hillsdale, NJ: Erlbaum.

Committee on Psychosocial Aspects of Child and Family Health. (1998). Guidance for effective discipline. Pediatrics, 101, 723-728.

Davies, G., McMahon, R., Flessati, E., \& Tiedemann, G. (1984). Verbal rationales and modeling as adjuncts to a parenting technique for child compliance. Child Development, 55, 1290-1298. doi: $10.2307 / 1129998$.
Fauchier, A., \& Straus, M. (2007). Dimensions of discipline by fathers and mothers as recalled by university students. Durham, NH: Family Research Laboratory, University of New Hampshire. Retrieved October 08, 2014 from http://pubpages.unh. edu/ mas2/DDI.htm.

Fauchier, A., \& Straus, M. (2010). Psychometric properties of the adult-recall form of the dimensions of discipline inventory. Durham, NH: Family Research Laboratory, University of New Hampshire. Retrieved October 08, 2014 from http://pubpages. unh.edu/ mas2/DDI.htm.

Gámez-Guadix, M., Carrobles, J., Almendros, C., \& FernándezAlcaraz, C. (2010). Physical punishment and long term consequences: The moderating role of parental context. Procedia Social and Behavioral Sciences, 5, 2093-2097. doi:10.1016/j. sbspro.2010.07.419.

Gartrell, D. (2001). Replacing time-out: Part one-using guidance to build an encouraging classroom. Young Children, 56, 8-16.

Gartrell, D. (2002). Replacing time-out: Part two-using guidance to maintain an encouraging classroom. Young Children, 57, 36-39.

Gershoff, E. (2002). Corporal punishment by parents and associated child behavior and experiences a meta-analytic and theoretical review. Psychological Bulletin, 128, 539-579. doi:10.1037//0033-2909.128.4.539.

Gershoff, E., Grogan-Kaylor, A., Lansford, J., Chang, L., Zelli, A., Deater-Deckard, K., \& Dodge, K. (2010). Parent discipline practices in an international sample: Associations with child behaviors and moderation by perceived normativeness. Child Development, 81, 487-502. doi:10.1111/j.1467-8624.2009.01409.x.

Graham, P. (2004). The end of adolescence. New York: Oxford University Press.

Grundy, E., \& Henretta, J. C. (2006). Between elderly parents and adult children: A new look at the intergenerational care provided by the 'sandwich generation'. Ageing and Society, 26, 707-722. doi:10.1017/S0144686X06004934.

Khoury-Kassabri, M., \& Straus, M. (2011). Discipline methods used by mothers: The contribution of ethnicity, socioeconomic status, and child's characteristics. Child Indicators Research, 4, 45-57. doi:10.1007/s12187-010-9077-z.

Knox, D., \& Schacht, C. (2008). Choices in relationships: An introduction to marriage and the family. Belmont, CA: Thomson Wadsworth.

Krevans, J., \& Gibbs, J. (1996). Parents' use of inductive discipline: Relations to children's empathy and prosocial behavior. Child Development, 67, 3263-3277. doi:10.1111/j.1467-8624.1996. tb01913.x.

Lansford, J., Chang, L., Dodge, K., Malone, P., Oburu, P., Palmérus, K., Bacchini, D., Patorelli, C., Bombi, A., Zelli, A., Tapanya, A., Chaudhary, N., Deater-Deckard, K., Manke, B., \& Quinn, N. (2005). Physical discipline and children's adjustment: Cultural normativeness as a moderator. Child Development, 76(6), 1234-1246.

Machado, C., Gonçalves, M., Matos, M., \& Dias, A. (2007). Child and partner abuse: Self-reported prevalence and attitudes in the north of Portugal. Child Abuse \& Neglect, 31, 657-670. doi:10.1016/j.chiabu.2006.11.002.

Maroco, J. (2007). Análise estatística: Com utilização do SPSS (3 $3^{a}$ ed.). Lisboa: Edições Sílabo.

McKee, L., Roland, E., Coffelt, N., Olson, A., Forehand, R., Massari, C., Jones, D., Gaffney, C., \& Zens, M. (2007). Harsh discipline and child problem behaviors: The roles of positive parenting and gender. Journal of Family Violence, 22, 187-196. doi:10.1007/ s10896-007-9070-6.

Meyerson, L., Long, P., Miranda, R., \& Marx, B. (2002). The influence of childhood sexual abuse, physical abuse, family environment, and gender on the psychological adjustment of 
adolescents. Child Abuse \& Neglect, 26, 387-405. 10.1016/ S0145-2134(02)00315-0.

Minuchin, S., Rosman, B., \& Baker, L. (1978). Psychosomatic families: Anorexia nervosa in context. Cambridge, MA: Harvard University Press.

Monteiro, R. (2010). Genealogia da lei da igualdade no trabalho e emprego desde finais do Estado Novo. In V. Ferreira (Ed.), A igualdade de mulheres e homens no trabalho e no emprego em Portugal: Políticas e Circunstâncias (pp. 31-56). Lisboa: CITE.

Moon, M., \& Hoffman, C. (2008). Mothers' and fathers' differential expectancies and behaviors: Parent $\times$ child gender effects. The Journal of Genetic Psychology, 164, 261-279.

Morawska, A., \& Sanders, M. (2011). Parental use of time out revisited: A useful or harmful parenting strategy? Journal of Child and Family Studies, 20, 1-8. doi:10.1007/s10826-010-9371-x.

Ochoa, G., Sánchez, J., \& Garcia, E. (1988). Familia y educación: Prácticas educativas de los padres y socialización de los hijos. Barcelona: Editorial Labor.

Olson, D. (2000). Circumplex Model of marital and family systems. Journal of Family Therapy, 22, 144-167. doi:10.1111/1467-6427.00144.

Olson, D. (2004). Family Satisfaction Scale (FSS). Minneapolis: Life Innovations.

Olson, D. (2011). Faces IV and the Circumplex Model: Validation study. Journal of Marital and Family Therapy, 37, 64-80. doi:10.1111/j.1752-0606.2009.00175.x.

Olson, D., \& Barnes, H. (2004). Family communication. Minneapolis: Life Innovations.

Olson, D., \& Gorall, D. (2003). Circumplex Model of marital and family systems. In F. Walsh (Ed.) Normal family processes (3rd ed.). New York: Guilford.

Olson, D., Gorall, D., \& Tiesel, J. (2004). Faces IV package. Minneapolis, MN: Life Innovations.

Olson, D., Gorall, D., \& Tiesel, J. (2006). FACES IV: Development and validation. Life Innovations, Inc.

Patrick, R., \& Gibbs, J. (2012). Inductive discipline, parental expression of disappointed expectations, and moral identity in adolescence. Journal of Youth and Adolescence, 41, 973-983. doi:10.1007/s10964-011-9698-7.

Peiser, N. C., \& Heaven, P. C. (1996). Family influences on selfreported delinquency among high school students. Journal of Adolescence, 19, 557-568. 10.1006/jado.1996.0054.

Pimentel, L. (2015). As pessoas idosas e os seus contextos familiares: Convite a um olhar diferente. In O. M. Fernandes \& C. Maia (Eds.), A família portuguesa no século XXI (pp. 171-178). Lisboa: Edições Parsifal.

Power, F., Nuzzi, R., Narvaez, D., Lapsley, D., \& Hunt, T. (2007). Moral education: A handbook. Westport: Greenwood Publishing Group.
Rebelo, J. (2008). Relações familiares e toxicodependência (Dissertação de mestrado não publicada). Faculdade de Psicologia e de Ciências da Educação da Universidade de Coimbra, Coimbra.

Relva, I. C., \& Fernandes, O. M. (2013). The Dimensions of Discipline Inventory (Unpublished manuscript). Departamento de Educação e Psicologia, Universidade de Trás-os-Montes e Alto Douro.

Roberto, A., Carlyle, K., \& McClure, L. (2006). Communication and corporal punishment: The relationship between parents' use of verbal and physical aggression. Communication Research Reports, 23, 27-33. 10.1080/17464090500535848.

Robin, A. (1998). ADHD in adolescents: Diagnosis and treatment. New York: The Guilford Press.

Silva, S. (2010). Mulheres e feminilidade em culturais ocupacionais de hegemonia masculina. In V. Ferreira (Ed.), A igualdade de mulheres e homens no trabalho e no emprego em Portugal: Políticas e Circunstâncias (pp. 293-332). Lisboa: CITE.

Straus, M. (2010). Prevalence, societal causes, and trends in corporal punishment by parents in world perspective. Family Research Laboratory, University of New Hampshire, 71(1). Retrieved October 08, 2014 from http://pubpages.unh.edu/ mas2.

Straus, M., \& Fauchier, A. (2011). Manual for the Dimensions of Discipline Inventory (DDI). Durham, NH: Family Research Laboratory, University of New Hampshire. Retrieved October 08, 2015 from http://pubpages.unh.edu/ mas2/DDI.htm.

Straus, M., \& Kantor, G. (1994). Corporal punishment of adolescents by parents: A risk factor in the epidemiology of depression, suicide, alcohol abuse, child abuse and wife beating. Adolescence, 29(115), 543-561.

Straus, M., \& Stewart, J. (1999). Corporal punishment by American parents: National data on prevalence, chronicity, severity, and duration, in relation to child, and family characteristics. Clinical Child and Family Psychology Review, 2, 55-70.

Straus, M., Sugarman, D., \& Giles-Sims, J. (1997). Spanking by parents and subsequent antisocial behavior of children. Archives of Pediatrics and Adolescent Medicine Journal, 151, 761-767. doi:10.1001/archpedi.1997.02170450011002.

Van Leeuwen, K., Fauchier, A., \& Straus, M. (2012). Assessing dimensions of parental discipline. Journal of Psychopathology and Behavioral Assessment, 34, 216-231. doi:10.1007/ s10862-012-9278-5.

Vidović, V., Jureša, V., Begovac, I., Mahnik, M., \& Tocilj, G. (2005). Perceived family cohesion, adaptability and communication in eating disorders. European Eating Disorders Review, 13, 19-28. doi:10.1002/erv.615.

Visani, E. (2014). Il Faces IV e il modello circonflesso. In E. Visani, S. Di Nuovo \& C. Loriedo (Eds.), Il Faces IV. Il modello circonflesso di Olson nella clinica e nella ricerca (pp. 16-62). Italy: Franco Angeli. 